\title{
How to Teach Academic Reading More Effectively: Learners' Remarks
}

\author{
Ketkanda Jaturongkachoke ${ }^{1}$, Supamit Chanseawrassamee ${ }^{2}$ \\ ${ }^{1}$ (The National Institute of Development Administration, Thailand) \\ ${ }^{2}$ (TOT Academy, Thailand)
}

\begin{abstract}
The present study was conducted at a Thai graduate school where for over 40 years of offering a reading course, approximately 20\%-80\%, making 50\% of students on average, could pass it. Thus, the coauthors analyzed the textbook while asking their students to complete a questionnaire. The participants were 54 graduate students. The tool employed in this study was an open-ended questionnaire. The three options about how each student felt about the textbook-appropriate, too easy, or too difficult-set out the study. Despite the quantitative results divulging the difference in considering the textbook as 'appropriate,' 'too easy,' or 'too difficult,' most of the respondents mentioned the inadequacy of some fundamental grammar lessons and vocabulary practices. Some participants required Thai translation for some parts which were difficult to comprehend. Some articles in the textbook were outdated, had no pictures, and caused confusion. The contents were also too long for the class to cover within the 45-hour time frame, resulting in the instructors' scurry to finish the textbook. To be specific, their evaluation of the textbook mainly relied on the test as the benchmark. A rich source of data is proved to be the open-ended questions where all participants can articulate themselves freely.
\end{abstract}

Keywords: academic reading skills, graduate students, SLA, Thailand

\section{Introduction}

It has long been traditionally accepted that Thai students learn by memorizing lessons and then use their memory to pass the examination. As the time transpired, such learning way was found to obstruct their creativity and sociability - the two features which are highly praised and required in global communication. To cope with such large-scale change, the Thai Education Ministry has made numerous endeavors to encourage Thai students to learn in a more analytical and efficient manner. For instance, according to Section 24 of the National Education Act B.E. 2542 (Thai Government, 1999), Thai learners must be provided with practical experiences so that they can apply the knowledge to the real applications, think by themselves, perform tasks efficiently, love reading, and gain lifelong learning. For love of reading, Professor Dr. Wichit Srisa-an, the Thai Education Minister in 2007, delivered the information about the reading rate of Thai people at the Reading Festival on June, 13-17 2007 hosted by the Ministry of Education. This festival was hosted in order to follow the policy of the Thai government to advance knowledge and raise education level. According to him, research findings revealed that a Thai person read approximately 7 lines per year. Based on such abysmal figure, it can be concluded that the majority of Thai people tend to disregard the importance of reading. The Ministry of Education, thus, needs to act in order to make Thai people love to read with the hope that the number of line per year will amplify (Ministry of Education, 2007).

Further, the Office of the Educational Council, Ministry of Education, Kingdom of Thailand (2011) has devised Strategy in Production and Developing Workforce of the Nation in the Second Decade of Education Reform B.E. 2009-2018. To follow the government policy especially in pursuing its AEC 2015 entry, Thai students will be taught in line with universal standards. In other words, Thai students are educated to become global villagers well-equipped with academic excellence, bilingualism/multilingualism abilities, modern conception, creativity, and social responsibility. According to the ASEAN Charter, English is the international

\footnotetext{
${ }^{1}$ Assistant Professor Dr. Ketkanda Jaturongkachoke is an Assistant Professor delivering lectures at the Graduate School of Language and Communication, the National Institute of Development Administration in Bangkok, Thailand. Her research and teaching interests include sociolinguistics, cognitive linguistics, and culture.

${ }^{2}$ Dr. Supamit Chanseawrassamee is a Senior Lecturer of English at TOT Academy, a training center of TOT Public Company Limited, in Bangkok, Thailand. Her major interests are English acquisition, bilingualism, and translation.
} 
language used in communication (Onwimon, 2013, p. 47). At a Thai public school, students are taught to conduct research, give presentation, integrate numerous bodies of knowledge, and apply knowledge/wisdom for the public good. Specifically, in the area of language literacy or bilingualism/multilingualism, public schools at all levels have to provide more language courses, basically English. For instance, at high school level, students are required to be able to write a 2,000-word paper in English (Triamudomsuksanomklao School, 2012). At university level, more and more international programs are offered; namely, in the academic year of 2006, a total of 844 international programs were offered by 53 higher education institutes. Among this number, 609 were offered by 30 public universities while the rest by private ones (Office of the Education Council, Ministry of Education, Kingdom of Thailand, 2007, p. 146). Most recently, according to 2013 University Web Rankings, there are 82 Thai universities. All of these universities are offering international programs in some form.

Presumably, the problem of low reading rate in Thai has led to a key problem - a low reading rate in English. Studying via traditionally rote learning method hampers students' creativity, analytical skills, synthesis of knowledge, and real-world application. That may be a reason why, despite numerous endeavors to enhance reading rate and English competency, Thailand is still facing the problems of low reading rates and low English proficiency.

\section{Problem Statement}

The world is spinning around requiring most young generations in non-English-speaking countries, if not all, to become literate in English because it is an essential communicative medium. Among the four basic skills, reading is believed to be the first step and a crucial part of literacy. Going from bad to worse, with the approaching ASEAN Economic Community (AEC), all ASEAN non-English-speaking countries, including Thailand, are vigilant to provide more and more English courses so that their citizens are well prepared to cope with and be accepted in the labor market at regional level. A full description and requirement of AEC can be found in detail in the co-authors' most recent article (Jaturongkachoke \& Chanseawrassamee, 2012). Nevertheless, comparing to ASEAN countries such as Singapore, a Thai child has relatively low experiences in reading - two books a year-while Singaporean children 40-50 and Vietnamese 60 (Pison, 2011). With such low reading rate, it is hard to imagine a high rate of literacy among Thai graduate students on an average. Deprived children who can memorize the annual Thai motto on Children's Day but cannot even communicate with other peoples in English are legion (Onwimon, 2013). In response, numerous Thai schools adjust their curricula by merely adding more English hours, activities, and foreign English teachers. Emergence of international programs is profuse, thereby allowing only rich kids to survive and compete in AEC (Onwimon, 2013).

Most likely, the problem caused by lack of reading experiences in Thai people has extended to English reading. The truth is inevitable not only among students at school but those in higher education. The horrific situation aggravates when students need reading skills to achieve their higher education. Reading skills are not easy to instill, develop, and enhance in a short time. Rather, readability development and improvement process is time-consuming and requires consistency. Mikulecky (1990), who highlighted the importance of reading readiness prerequisite asserted that second language learners will be able to understand texts in Standard English only when they can "develop new schemata of the language, text, and interpretation, as well as schemata of alternative cultural practices and values" (p. 5). Vathakanon (2005) and Sosothikul (2007) concurred that to be able to read well, i.e. understand the written text, students should understand the meaning of a word; the system of elements and modifiers in a sentence; as well as punctuation, pronoun, and conjunctions. Such knowledge will enable readers to identify the topic, find the main idea, understand the writer's purpose, and draw the conclusion of a written text. Such ability can emerge only via constant critical reading and reading analysis. Teaching students to memorize some rules or lessons-so called rote learning-for tests inevitably leads to deprivation. Based on Mikulecky (1990), it is very hard for native speakers to learn to read, and even harder for non-native students, who do not know how to understand, analyze, and synthesize written texts even in their mother-tongue texts. As a consequence, students should be first educated on why they have to learn to read and what the negative effect of rote learning is (see Mikulecky, 1990; Musumeci, 1997; Chalaysap, 2009; Vathakanon, 2005, for instance).

The present study was conducted at the National Institute of Development Administration, or its catchy acronym NIDA. To produce quality graduates, NIDA thus provided its graduate students with content subjects and other necessary skills required by the current labor market situation. For instance, all students in whichever field of study will be prepared first both computer and language literacy. To react to rapid economic and political changes, e.g. the ASEAN Economic Community, the Institute requires its students to take at least two English courses which are LC 4001: Reading Skills Development in English for Graduate Studies and LC 4002: Integrated English Language Skills Development. LC 4001 is taught by Thai instructors while LC 4002 by English native speakers. Any student who fails LC 4001 must take LC 4011: Remedial Reading Skills Development in English for Graduate Studies. For over 40 years of offering LC 4001 courses, only 
approximately $50 \%$ on average (coming from $20 \%-80 \%$ of each school) could pass the LC 4001 course. Most recently, in the first semester of the academic year 2012, 178 out of the entire 325 LC 4001 students (55\%) passed, while the 147 others (45\%) failed. A reasonable explanation for this slightly rising rate in this year is the lowering 3 scores for the passing criteria. Surprisingly, there have been no studies examining the real cause of these students' failure in the domain of the textbook. Particular, students should have played a significant part in expressing their attitude towards the textbook. Instead, previous studies looked into other areas, e.g. LC 4001 students' translation and comprehension abilities; reading behaviors of male and female students; and reading materials provided in the remedial LC4011 course.

To begin with, Chalaysap (2009) examined sentence comprehension by comparing the effectiveness of the syntactic structure identification training and of integrated reading strategy. The findings suggested that many students overlooked the importance of connectives which led to misinterpretation of the written texts. Later, in another research study, all LC 4011 instructors jointly looked into their students' participation in generating academic reading materials (Chalaysap et al, 2010). The results showed that the reading achievement scores of the students who generated their own reading materials were significantly greater than the scores of those who didn't. In brief, the research revealed that learners' participation in text generation will enable them to read English more effectively. Such participation was a viable option for teaching English reading. In another survey, NIDA students' outside-class reading behaviors are not generally different in terms of gender. While female students tended to read more English textbooks, male ones inclined to read books related to real-life experiences. Significantly, students preferred the Institute to use real-world texts rather than simplified ones (Chalaysap, 2011). In her review of related studies on learning English as a second language, Izzo (1981) asserted that many research studies conducted paid attention to the students' attitudes toward English, English native speakers, the class, the teacher, and themselves as factors leading to learning success (p. 8), leaving the textbook into the policy maker or the course director. Eskey (1986) claimed, “...the first concern of any reading teacher is to find, or create, a body of material that his particular students might find interesting to read, and then to do everything in his power to make it as comprehensible to them as he can" (p. 4). Knowing needs, abilities, and interests of their students enable instructors to make the classroom more effective (Anderson, 1999, p. 115). Based on these gurus' research studies, the co-authors wondered whether the reading material, i.e. the textbook, used in the course may be a key factor which brings about success or failure of their students' success in their academic reading.

Originating from such postulation, the co-authors requested their 64 students to complete a questionnaire, with 54 returned. Open-ended questions revolving around the textbook assessment enable the participants to articulate their opinions freely. These respondents' replies will help educators, lecturers, or course directors/administrators to know the true factors of students' achievement and disappointment. Such knowledge can positively assist the course administrators in planning and offering a better English course for newcomers in the future. The idea can be also applied to any other reading courses at a wider range. As research studies on material employed in the instructions and adult reading experiences are rare (Burt, Peyton, \& Adams, 2003), this type of paper is thus welcomed by academic journals for effective teaching (Connolly, 2009).

III. Some Perspectives On Reading Theory And Research

Reading ability is the supreme symbol of an educated person (Nunan, 1999, pp. 249-250). Despite a tremendous amount of time, money, and effort, many students are deemed illiterate. In the realm of higher education, the readability in English is a must because quality papers undergo meticulous peer review and proofreading, thereby being written in Standard English. Heller (1997) points out that in schools where English is a dominant language, English native speakers tend to be more successful than non-native students, indicating that English literacy strongly affects on students' academic achievements (p. 87). This is also true for Master's degree and doctoral students at NIDA because they are required to read English articles and textbooks. Without high readability in English, they can not complete NIDA's requirements and graduate.

Here comes the purpose of reading. Nunan (1999) proposes that a person reads different texts for different purposes and with different cognitive strategies. For example, Nunan (1999) himself read novel and poems for pleasure and inquisitiveness, academic journals like TESOL Matters for a specific piece of information, and wine label for grape varieties (pp. 250-251). To read these different types of text, he also used different cognitive processes. For accuracy and pleasure, he read slowly and cautiously. He skimmed and scanned to get general idea and/or some specific information in the text (Nunan, 1999). In the present study, LC 4001 students are taught to be able to understand the entire text. They have plenty opportunities to learn to apply diverse reading strategies including skimming and scanning. As shown in the findings section later on in this paper, the major purpose of most Thai students in this study is not for sustainable readability or reading comprehension in Mikulecky's (1990) definition, but for passing the tests only. It is of the co-authors' concern whether reading should be taught only or some correct attitude toward English learning should be instilled alongside. 
When discussing the purpose and attitude toward English learning, it is worth mentioning some gurus' perspectives in the reading field, e.g. Crandall (1979); Silberstein (1993); Anderson (1999); Nunan (1999); Burt, Peyton, \& Adams (2003); and Chalaysap (2011). Their comments exactly coincided with each other that good language learners can achieve their learning when the lessons suit their real-world requirements, e.g. the dominant language at home or at work. English learners who require English for understanding technical texts, for employment, and for communicative needs have greater enthusiasm to learn the language (Crandall, 1979; Silberstein, 1993). Students can learn better and more effectively when teachers provide ample opportunity for them to fully comprehend the material in a non-threatening environment (Burt, Peyton, \& Adams, 2003). Chalaysap (2011) found that female students were apt to read more English textbooks than male ones who inclined to read books related to real-life experiences. Regardless of gender, a person can learn best when the content is personally related to his past experience, present concerns and life experiences (Nunan, 1999, p. 15). Importantly, the more suitable the materials used in the classroom, the more effectively they will achieve their goals of learning (Burt, Peyton, \& Adams, 2003). As these sages mentioned the significance of materials, i.e. texts, employed in the classroom, the co-authors in the present study examine the readability development of the students in the domain of the textbook in particular.

Regarding the textbook, students should not learn reading via "rote exercises" (Mikulecky, 1990, p. 28). Instead, they should be taught to learn why a specific lesson or a certain passage is needed for them to read. With a small number of exceptions, ESL (English as a second language) readers usually do not learn to read as much as learn to decipher the code. "Decipherment is essentially an activity in which form triumphs over content" (Child, 1988, p. 128). As LC 4001 is the basis of all other courses provided in the higher education where all students are required to read English textbooks and academic articles, this reading course is vital to prepare these newcomers to familiarize and ready themselves to the texts in their specific field. For the basis of understanding how a sentence, a paragraph, a passage, or even a whole chapter is formed; students are to learn basic structures of the language. In the second half of the class, they learn the previewing, predicting, skimming, scanning, so on and so forth. Nonetheless, many students do not have strong foundation of English grammar. In other words, they are not familiar with the form, thereby being unable to decipher the code and/or relationship of different parts of the sentence. Mikulecky's (1990) proposition started from the decoding stage, while LC 4001 started from the sentence level comprising types of phrases, clauses, and sentences. Students who do not possess a solid preparation for the part of speech, thus, can not catch up with those who do. Such lack of basic knowledge inexorably led to a failing proclivity.

Musumeci (1997) suggested that it will be useful to teach students to learn to read via grammatical and syllabic rules. In her opinion, students should learn how clauses and sentences are constructed. As students learn at their own pace, "no precise timetable for language acquisition can be prescribed" (Musumeci, 1997, p. 51). Conversely, this is impossible for degree curricula. The textbook used in LC 4001 class purports to be an easy and convenient package for the instructors to teach and follow. Still, should we all instructors turn to think of our students' paces of learning and their own prevalent goal of teaching? As Mikulecky (1990) pinpointed that students should have a strong foundation of English first and as Musumeci (1997) stated that students learn at their personal rates, there are some opposite viewpoints.

Mikulecky's (1990) and Musumeci's (1997) concept of reading readiness prerequisites is firmly argued by Peregoy \& Boyle (2001). According to the latter group, there is adequate evidence which showed that many English speakers and learners are proved to be able to read without any reading readiness prerequisites. "For native English speakers and English learners alike, many reading readiness subskill prerequisites turned out to be unnecessary hindrances to literacy development" (Peregoy \& Boyle, 2001, p. 153). This notion accords with Rigg and Kazemek (1993) who claimed that for adults "the whole language" is the most suitable approach (p. 35). Savage (1993) further confirmed that "learning should be directly related to application (p. 19). Rigg and Kazemek (1993) asserted that "language is whole (hence the name) and that any attempt to fragment it into parts, whether these be grammatical, vocabulary lists, or phonics "families," destroys it. Language must be kept whole or it isn't language anymore (p. 35).

Anderson's (1999) ACTIVE framework regards reading as

"an active, fluent process which involves the reader and the reading material in building meaning. Meaning does not reside on the printed page, nor is it only in the head of the reader. A synergy occurs in reading which combines the words on the printed page with the reader's background knowledge and experiences. Readers move through the printed text with specific purposes in mind to accomplish specific goals" (p. 1).

He proposed "ACTIVE," an acronym originated from the first letters of six ESL classroom strategies stands for: (1) activate prior knowledge, (2) cultivate vocabulary, (3) teach for comprehension, (4) increase reading rate, (5) verify reading strategies, and (6) evaluate progress. According to Andersen (1999), rote memorization and repetition is, to some degree, facilitate vocabulary acquisition and expansion. He also suggested that to achieve the reading goals, teachers should consider the five factors which affect the 
instructional plan comprising: time, progression, student groups and cooperative learning, variety, and students' needs, interests, and abilities (Anderson, 1999, p. 114). Respecting Anderson's precept (1999), the co-authors investigated the students' attitude toward the reading material or the textbook in the course.

The co-authors did the research while keeping all these theories in mind. The next section presents the co-authors' key purpose of the present study.

\section{Purpose Of The Study}

The textbook is a crucial element in English teaching and learning (Anderson, 1999). The co-authors thus desired and decided to examine whether or not it has a negative effect on the students' reading proficiency. To raise the passing rate of LC 4001 students, the co-authors thus analyzed the LC 4001 textbook according to Mikulecky's (1990) suggestions and asked the students for their favorable/unfavorable comments on the textbook. In brief, the present study is aimed to find out how graduate students feel about the textbook of the course the LC 4001: Reading Skills Development in English for Graduate Studies (2012). All their critical commentaries will be taken into account. The course administration or the Graduate School of Language and Communication may agree or disagree with these respondents' comments. The co-authors optimistically hope that these comments will lead to a necessary adjustment of the textbook and betterment of the course in the future.

\section{Methodology}

To enable those who may be unfamiliar with the Thai education system, the institute where this study took place, and its English course; the methodology section will describe the nature of the institute, course, and participants in the current research study.

\subsection{Overview of the National Institute of Development Administration}

To explain the nature of the Institute, it is best to refer to its Annual Report (2008). Inception on April 1, 1966 of the National Institute of Development Administration came from the gracious initiation of His Majesty King Bhumibol Adulyadej or King Rama 9. Continuously deploying both knowledge and morality, NIDA has always created wisdom, ethics, and accountability for the benefit of Thai society, the nation at large, and the ASEAN community as a whole. Such constant development attempts are aimed to enhance educational quality and advance NIDA toward a world-class institution with potential for self-adjustment to real-world changes and with intense competitiveness. To achieve its goals, NIDA has visualized itself "to become a national leading institution which creates leaders and knowledge body for changes on the universal level."

To cope with all ongoing challenges, core values need to be set up. Six shared values are comprised of WISDOM, which conveys more than the literal meaning of the word in general. Instead, WISDOM here is an acronym originated from the first letters of NIDA's six core values including (1) world class, (2) innovation, (3) sage, (4) discipline, (5) open-mindedness, and (6) morality. According to NIDA Annual Report (2008, p. 3), each element has its own definitions as follows:

"W: World Class refers to NIDA community's strong determination to consistently improve its institution to become a world-class university.

I: Innovation refers to NIDA community's dedication to resolutely devise innovations for the Thai society.

S: Sage refers to NIDA community's emphasis on developing everybody to be well equipped with intelligence and brilliance.

D: Discipline refers to NIDA community's fervent wish for everybody's adherence to disciplines.

O: Open-mindedness refers to NIDA community's resolution to promote open-mindedness.

M: Morality refers to NIDA's community's tenacity to wish for everybody's compliance with morality, honesty, and good corporate governance principles"

(National Institute of Development Administration, 2008, p. 3)

With its key goal to become a world-class university, the Institute predominantly focuses on its curricular quality and standards. Its generous supports for faculty's research toward the common good of society, the country, and all mankind are quite apparent. To date, NIDA has produced a large number of master's degree and doctoral candidates whose quality is highly and widely satisfactory to all employers. Over 30 alumni of NIDA, for instance, have taken up appointments as provincial governors. Others became renowned CEOs of organizations at national and global level (National Institute of Development Administration, 2013, p. 3). In the past, English might be only a 'preferable' qualification of job applicants. For the time being, the English proficiency becomes a 'must' for almost all job applications, while other languages like Chinese, Japanese, and French will be advantages. To cope with such change of high standards of English requirement, NIDA has put greater and greater importance upon English ability of all its students. One of its constant efforts is to have the Graduate School of Language and Communication to provide all new students with LC 4001: Reading Skills Development in English for Graduate Studies. 


\subsection{Nature of the Course LC 4001: Reading Skills Development in English for Graduate Studies}

The course LC 4001: Reading Skills Development in English for Graduate Studies is a 45-hour noncredit course offered by the Graduate School of Language and Communication. The class meets once a week on Tuesdays from $1 \mathrm{pm}$ to $4 \mathrm{pm}$, or for 3 hours per day for 15 weeks. The course is provided for all new full-time graduate students at the National Institute of Development Administration. The course "is aimed at enhancing students' understanding of English structure such as sentence types, core parts, headwords and modifiers. This will enable students to develop their English reading skills necessary for academic texts and research papers. Emphasis is placed on developing students' skills in reading for main ideas, drawing conclusions and making inferences, using context clues to arrive at the meanings of unknown words, skimming and scanning, and developing their discourse competence, including critical reading skills (Graduate School of Language and Communication, 2012, p. i). Upon the completion of the course, students are encouraged to be able to:

1) "Grasp the meaning of long and complicated sentences through sentence analysis;

2) Develop sentence interpretation skills;

3) Detect meanings of unfamiliar words through context clues and word analysis (e.g., roots and affixes);

4) Use the dictionary to properly understand the meanings of difficult words or the multi-meanings of a word;

5) Identify the topic sentence and main idea of a reading selection;

6) Identify the purpose of a reading selection;

7) Develop skimming and scanning skills;

8) Use discourse markers appropriately; and

9) Further develop their skills in using context clues and interpreting implied meanings of a reading selection" (Graduate School of Language and Communication, 2012, p. ii).

LC 4001 in the present study started from August 8 to November 27, 2012. In the first part, before the midterm examination, students learn about basic sentence patterns; phrases, clauses and sentences; reduction of adjective and adverb clauses; core part, headwords and modifiers; sentence comprehension and interpretation; and dictionary usage. The midterm test took place on October 9 from 1 to $4 \mathrm{pm}$. In the second half starting from October 16, students learn about topic sentences, discourse markers, movement of thoughts; main ideas and purposes of reading; drawing conclusion and making inferences (skimming); multi-paragraph reading; and article/chapter reading for the finals. During the first part, there were always some questions related to some specific grammar points. Along the course, the co-authors thus provided their students with some more interesting worksheets on a vast variety of types: extra vocabulary exercises, grammatical lessons, and reading assignments. The textbook will be analyzed in compliance with Mikulecky's (1990) a short reading course outline in 5.3 below.

\subsection{Nature of the Textbook for Course LC 4001}

The course LC 4001: Reading Skills Development in English for Graduate Studies is provided by the Graduate of Language and Communication to all new Master's degree students in the regular program. The textbook was exclusively produced to prepare, ready and align all these students' English reading proficiency. As graduate students are required to read English-language textbooks and academic papers, they need to learn how to read, understand, summarize, paraphrase, or translate the English text.

The textbook is a black and white version without any picture. It has been updated through time, and the version used during the present study was most recently revised in 2012. The reading material is straightforwardly classified into four units which are: Unit I: Sentence Structure, Unit II: Context Clues and Sentence Interpretation, Unit III: Paragraph Elements and Unit IV: Previewing, Skimming \& Scanning. The mid-semester examination will cover Units I and II, whereas the finals will elicit from Units III and IV. Below each unit is discussed with examples one by one.

Unit I: Sentence Structure. This Unit reviews sentence patterns (e.g. simple, compound, complex, and compound-complex sentences), clauses (e.g. adjective, adverb, noun clauses) clause reduction, phrases (e.g. participial, prepositional, gerund phrases), core parts, and modifiers. For example, students should know that the sentence: "The notion that some people are simply born artistic - and that there is a profile that can help organizations identify them-is quite firmly entrenched" is of a complex type. The core part is: "notion is entrenched." There are two noun clauses: that some... artistic and that there is...profile. The verb "entrenched" is modified by the adverb "firmly" (Graduate School of Language and Communication, p. 30).

Unit II: Context Clues and Sentence Interpretation This Unit covers frequently used roots (e.g. im-, miss, dis-, -ee, etc.), contextual clues, as well as sentence comprehension and interpretation (e.g. word order, time, tenses, voices, moods, punctuation, modal auxiliaries, etc.). For instance, students should know that the sentence: “All politicians are somehow corrupt, without exception. Just look at our mayor who's under indictment, and one congressman who recently resigned" can be interpreted as "The mayor and the congressman are examples of corrupt politicians." Or, it can also be understood as: "All politicians are corrupt" (Graduate 
School of Language and Communication, 2012, p. 89).

Unit III: Paragraph Elements. This unit discusses topic sentence, main idea/clue, transitional marker (e.g. continuation of thought, comparison, opposition, concession, time, etc.), movement of thought (e.g. chronological order, particular to general, general to particular, question to answer, etc.), writer's purpose (e.g. illustration, cause and effect, generalization, etc.), skimming, scanning, as well as reading paragraphs and multiparagraphs.

Unit IV: Previewing, Skimming \& Scanning. For this unit, students are required to read an 8-page academic paper on "The Business Approach to Sustainable Development" published in Journal of SID in 1989, volume 2 no. 3 . The paper covers a wider range of topics including economics of sustainable development, language of business and environment, sustainable development in practice (including clean technology, industry clearing house, and marine pollution), and postscript: ICC program on sustainable development.

When comparing these contents with Mikulecky's (1990) reading course contents, the co-authors found that it is wiser for teachers of English native speakers as well as second language learners to focus on specific skills for poor readers or passive "comprehenders" (p. 27). Such lessons may involve basic grammar and vocabulary. Then, these learners will be taught about previewing and predicting. They should learn not to read every word by scanning the text and learn to read faster. Students learn to conceptualize and perceive a text. Spelling, grammar and reading skills will be integrated at this stage. Students will also gain the word knowledge followed by topic identification, main idea, and textual organization (e.g. generalization, time order, causeeffect, comparison-contrast, etc.). At the end of the course, students will be able to perform skimming and summarizing efficiently. Compared with Mikulecky's (1990) reading course contents, the LC 4001 textbook seemed to cover all the contents except for filling the gap for weak students. As said by Mikulecky (1990), Musumeci (1997), and Vathakanon (2005), good readers should have good basis of decoding and grammar of English, then the above analysis of the LC 4001 textbook revealed such gaps. However, this is part of teacherbased analysis and may be inadequate for the course administrator to make some decisions.

An analysis of the questionnaire completed by the respondents at the end of the course (November 27, 2012) focuses on their attitudes toward the textbook in particular. Such discussion highlights how LC 4001 students feel about the textbook, see the importance of English reading, and offer suggestions which may lead to the betterment of the course. The findings of the well-designed educational program like LC 4001 course, a search for the effectiveness of the materials used, and the feedback from the learners help ascertain whether the theory which the textbook was based on will produce a desirable effect upon students' learning or not (Connolly, 2009).

\subsection{Nature of the Participants in this Study}

On the last day of class but before the finals, questionnaires were distributed, filled in, and returned from 54 students (male: 26; female: 28) out of the entire 64 in LC 4001: Reading Skills Development in English for Graduate Studies provided at the National Institute of Development Administration, a postgraduate institution, in Thailand. Their ages were between 22 and 31, with an average of 24 years old. The participants came from two schools: the Graduate School of Public Administration (GSPA) and the Graduate School of Development Economics (GSDE). The GSPA participants obtained their Bachelor's degrees in political science, social science, business computer science, and management. The GSDE participants obtained their Bachelor's in economics, sociology \& humanism, marketing, management, engineering, and accounting. The co-author did not investigate the difference of opinions based on gender and field of study because all of these graduate students are required to read the same English textbook. Based on Chalaysap's work (2011), there was no difference between males and females in the rate of reading English texts.

The admission procedure of the participants varies from one school to another and from an individual major to another; therefore, there was no base scores for further comparison and/or contrast analysis. To be enrolled in LC 4001, all these students had passed a written examination and/or an interview. For instance, students with honors only took an interview for admission. As the admission procedure is different from one student and/or program to another, the score of their admission was not included as a factor in this study. As the newcomers obtained their Bachelor's degrees, they were assumed to have a medium to high degree of English proficiency. The finals showed that 38 out of 64 , or equivalent to $59 \%$, passed. Overall, for the first semester of the academic year 2012, 178 out of 325 LC 4001 students (55\%) passed, while the 147 others (45\%) failed. Based upon the scores and the passing rate of the course LC 4001, the fact is apparently different from the precedent assumption.

\subsection{Questionnaire}

In the current study, both authors acted as the participatory co-researchers as they were the two instructors, among ten, of the course LC 4001. The two authors asked their students to express their feeling towards the textbook because learners are the most important part of learning and teaching process. Even though 
the textbook has been adjusted through time, the betterment of the textbook cannot be possible without learners' comments. In the work of Chalaysap et al (2010), the reading achievement scores of the students who created their own reading materials were significantly greater than the scores of those who did not. Therefore, inclusion of students' comments is deemed helpful for the textbook improvement. The participants were asked to complete the questionnaire in either Thai or English as they wished. All of them said that their best language is Thai; therefore, they all wrote their answers in Thai. In the questionnaire, they were specifically asked to reveal how they feel about the textbook. Three options available for them to select only one were:

(1) The content of the textbook is 'appropriate;'

(2) The content of the textbook is 'too easy;' or

(3) The content of the textbook is 'too difficult.'

Percentage of each option was then tallied and calculated into percentage in order to find the respondents' overall judgment. Open-ended questions for their free articulation of opinion were also provided. It is also interesting to know that the words or questions appearing in the questionnaire are meaningful and should be treated in a profound way. Without open-ended questions or further informal discussion, the question may be deemed unclear to the respondents, thereby resulting in a misleading analysis of the authors/researchers.

The finals took place on December 11. The questionnaire was distributed on November 27, 2012. Thus, respondents' upset might be caused by the mid-semester test results, but not from the finals or the final grade

\section{Findings And Discussions} number.

This portion discloses the number of each option selected by 54 participants. Table 6.1 shows such a

Table 6.1 Number of each option $(N=54)$

\begin{tabular}{|c|c|c|}
\hline Option 1: Appropriate & Option 2: Too Easy & Option 3: Too Difficult \\
\hline 34 & 6 & 14 \\
\hline $63 \%$ & $11 \%$ & $26 \%$ \\
\hline
\end{tabular}

Table 6.1 reveals that most respondents of both sections $(63 \%)$ see that the textbook is suitable for the course. As each option entails plenty of comments and complaints, it will be better to let respondents express their comments freely. These constructive remarks should be straightforwardly reported using the respondents' own words because they were not only involved in the presentation activity, but also other pedagogical concepts. As all the replies were in Thai, the co-authors did the translation job for all the respondents. The following answers have shown that their constructive suggestions are invaluable to all instructors, educators, and program administrators for the course improvement in the future. Subheadings $6.1-6.3$ below reveal comments made by students on the three options one by one.

\subsection{The content of the textbook is 'appropriate' (63\%)}

In Thai traditional custom, students are not culturally supposed to act against the teacher (Jaturongkachoke \& Chanseawrassamee, 2012). Therefore, based on the number of this option is higher than the other two options, it came to no surprise that most of participants considered the textbook appropriate. Nonetheless, examining previous studies conducted with Thai learners (see Chanseawrassamee, 2012; Jaturongkachoke \& Chanseawrassamee, 2012, for example), the co-authors found that Thai participants always add their suggestions in their open-ended answer. Thus, it is far better to rely on their freely written answer than just the multiple choice. The respondents' constructive answers are shown below.

- The contents in the textbook should be more updated to cope with the current economic situations.

- Contents and exercises of the textbook should be as tough as the questions in the test. The textbook should have some pictures for better understanding. There should also be some previous tests for practices.

- The contents are appropriate, but the exercises should be similar to questions in the test. The contents of the textbook should cope with the present situations. There should be a list of vocabulary in the appendix for ease of reading and definition finding.

- There should be more exercises in a well-rounded manner so that students can do the exam and understand the contents more clearly.

- $\quad$ The textbook is not updated. The examples are too old-fashioned.

- In the first part of the textbook, there should be more exercises. The exercises provided in the textbook are far easier than those in the test. There should be more contents in the domain of vocabulary frequently found in English articles.

- The contents and the time are matchless. These are too many contents.

- I want to know more about techniques of doing the exam. The test is too difficult. I like the new worksheet provided by the teacher. 
- The textbook is appropriate. After reading the book, I can analyze English articles. However, the criteria of passing is quite high. There should be more exercises because there are few details in the textbook.

- The contents of the textbook is proper. However, the difficulty level of the test is much higher than the textbook. The textbook has only written texts and this made me bored when reading.

- The contents are quite difficult, but suitable for Master's degree students. The contents are quite complete and can be applied to the daily life. The course enhances both my grammar and reading skills. The vocabulary is suitable for Master's degree students, but it is much easier than the questions in the test. Thus, the scores in the midterm and finals are fairly low.

- The contents are proper, but they should be more compact for only one semester. The contents should be more updated.

- The contents in this course are appropriate. The sequence of the contents are great.

- The contents are proper, but they are too much. The contents should be reduced to match the course schedule. To finish the entire book is too hurried.

- There should be more vocabulary exercises because many words have similar meanings. The articles should have outstanding remarks of each sentence. There should be some highlights or cautions for students to notice.

- The textbook has both difficult and easy contents. This feature enables students to pratice a vast variety of exercises. This is a very appropriate curriculum.

- There should be a CD for students to practice at home.

- The contents are suitable for Master's degree students. However, students who can not adjust themselves to the English class and the textbook may need some more preparations. Unlike studying English at the undergraduate level, in this course there are a lot of details, deep insights, etc. This made students to try harder.

- The textbooks should be updated. There should be more explanation in the grammatical part. Some points/topics have inadequate explanation. Contents in the exercise parts are old-fashioned.

- There should be listening and speaking parts or any other skills in our daily life. There should be some more contents which can be applied to the real life.

- There should be some Thai explanation and a lot more exercises.

- Covering all the contents is totally a rush. Exercises in the textbook are not enough.

- There should be Thai explanation for better understanding. There should be more learning materials for studying at home.

- The study on 'clause' should be reduced. There should be more emphasis on main ideas and some grammatical rules.

- There should be more examples. Some examples provided in the textbook are unclear and not inclusive enough.

As abovementioned, Thai students are reserved and tend to yield to the authority-here the instructors. Particularly, LC 4001 is a required course. Below-B grades mean that the enrollees have to retake the course by enroling in the remedial LC 4011 course. Therefore, even though the respondents feel that the textbook is not suitable for them, they will say it is. Instead, in the open-ended part, they reveal their true feelings.

In brief, this group of students has a positive attitude toward the textbook. To be specific, most of them know that the textbook matches their studies at the Master's degree level. Nonetheless, they have some suggestions for the course directors and instructors. As a rule, some grammar and vocabulary exercises are insufficient. The contents of the textbook should be more updated. For better understanding, there should be Thai explanation in some parts. The contents are too legion, thereby being incompatible with the period of study. Some topics such as clauses should be reduced, whereas those on vocabulary and main idea should be added. Some mentioned that listening/speaking skills and other language skills necessary to their daily life should be more emphasized. These requests accord with many researchers in English acquisition that learners can succeed in English learning when the material used in the classroom match their real-world experiences and expected applications (see Crandall, 1979; Krashen, 1985; Nunan, 1999; Anderson, 1999; Richards \& Rodgers, 2001; and Burt, et al, 2003, for example).

\subsection{The content of the textbook is 'too easy' $(11 \%)$}

When the co-authors first tallied each option, they had a first impression that the respondents in this categories were arrogant and looked down upon the textbook. However, upon reading their answers to the openended question, they found some surprising truth as follows:

- The explanation of each exercise is unclear. For instance, there can be more than one possible answers.

However, the instructions do not say so. 
- The content of the textbook is suitable for Master's degree students; however, it is too easy compared to the midterm test. This is because the test is much more difficult than the content in the textbook. Thus, many students can not do the test.

- Compared to the sentences in the test, the examples provided in the textbook are much easier and can be identified more easily. The sequence of the contents is appropriate, though.

- The examples in the textbook are much easier than the questions in the test. In the test, the vocabulary use is more profound and formal. Therefore, there should be text adjustment every year so that the content will be updated and proper to current situations.

- The contents in the textbook consist of some clues which help students to find answers more easily. When compared to the textbook, sentences in the midterm test are more complicated and hard to identify the correct answers. Also, exercises in the textbook are legion. As a consequence, the instructor has to accelerate her teaching. There should be a reduction in the number of exercises for temporal appropriateness.

Once the co-authors read the answer in the open-ended question, they found that these students were deeply rooted in the English study. They tried to help improve the textbook in terms of its update, length, number of exercises, and last but not least, toughness of the textbook compared to the test. Thus, when students said that the textbook is 'easy,' many instructors may not have thought of the real meaning of their comments. These students are so profound that they can compare the toughness of the books and the test. On one hand, to both authors, this is a new dimension of learning and teaching English. This book has been used for decades; no researchers have ever looked into the relationship between the text and the test. On the other hand, the comparison between the text and the textbook reflects the truth that Thai students learn English just for passing the requirement, not for making meaning and further use such ability in their daily life or even their job in the future. The findings comply with many gurus including Onwimon (2013). Learning content subjects like English just for the test is a waste of time, energy, and money at all levels: personal, communal, national, and international. Students should be properly and fully educated about the significance of language learning.

\subsection{The content of the textbook is 'too difficult' $(26 \%)$}

The low percentage of passing students is a factor that caused no surprise. There are large numbers of constructive suggestions which made the authors appreciate these students' honesty and sincerity to make a difference to the course. Their simple but invaluable suggestions made this study worthwhile, not only to the coauthors as instructors but also to publishers, educators and course administrators. The importance of bilingualism is obviously highlighted.

- $\quad$ There are few exercises.

- $\quad$ The textbook should have some pictures to add some more excitements.

- There should be Thai explanations to some topics, e.g. noun clause or sentence structure. Thai explanation will enable students to understand the textbook more clearly.

- Some contents are inappropriate, e.g. noun clause. The content of the lecture is not clear enough. For this topic, it's too difficult for students to learn by themselves. Some students may have little fundamentals in English. This also made it even harder for them to understand the textbook. There should be someone who will review the contents of the textbook for more appropriateness. Because of such limitation of the textbook, the task falls on the teacher. This is because sometimes the contents in the textbook are different from what the teacher said. In my opinion, the teacher taught much better than the book said. Overall, the textbook is appropriate in some parts.

- $\quad$ For better understanding, there should be some more explanations.

- There should be Thai explanation. There should be some more examples because examples enable students to do exercises much better.

- The contents of the textbook excluding the exercises are written in a complicated way. The exercises in the textbook are much easier than those in the test. The test is too difficult. The textbook does not pave the way for students from the beginning.

- There are a large number of contents, but a little time to study. I wonder if the grammar part can be taught separately so that all students can understand it more clearly. The contents in the textbook are much easier than those in the test.

- The teacher teaches according to what stated in the textbook. She should add some more teaching techniques, invent new test-taking techniques, and change her teaching style. The textbook is boring and hard to understand. There is no fundamental course, so I can't understand the written text in the book. Some exercises still confuse me.

- The contents of the textbook are too difficult to understand. There are too many details. There should be only important points or techniques for understanding. Some points are not used in daily situations. 
- As for contents of the textbook, some Thai explanations should be added. As for exercises, easier vocabulary words should be used.

- There are no summaries, charts, and contents in Thai at all.

- Grammar is hard. Sometimes the book has no explanations for students who are not good at grammar. There should be basic grammar contents for students who are not good at grammar or lack grammatical knowledge. At least, students should be prepared to know what grammar elements to use and where. There should be basic grammar courses for students who volunteer to enroll in so that they can further their English study and move on with the class. If the book is beautiful, it will attract students to read more.

The above comments are consistent with the comments provided by the two previous groups-seeing the textbook appropriate and too easy compared to the mid-semester test. In other words, the specific word: appropriate, too easy or too difficult, seem to be insignificant when delving into their comments. This can be discussed in the aspect of saving-face culture. That is, students do not dare to express their negative feelings outwardly. Rather, they use the blank space to show that part of mind.

Bilingul textbooks are still in the picture. Based on the above suggestions/comments, the co-authors have found them all constructive and beneficial for improving the textbook or even the course per se. However, it must be at the administrative level to decide if grammar courses should be provided or not. There should be some considerations as whether the Thai subtitles or explanations may hamper their reading English-only textbook in the course or not. The co-authors wonder if the Thai explanation may function as the Thai subtitles in the movies. The English-only textbook may help the students much better in enhancing their reading capability. Even so, the idea of grammar preparation is interesting. Many bilingual ESL courses both locally and internationally have been proved to be the first step for students whose English is not strong enough. How can students understand the meaning if they do not even know parts of speech and core parts. Many students mentioned that they even do not know the noun clause.

As widely known, 'teacher' is a crucial factor of learning achievement (Izzo, 1981, among many others). Many English-education experts then suggest numerous pedagogical approaches for instructors. Even though this paper is not specifically focused on the way the instructor taught, a student used the questionnaire as a venue to express her honest feeling, "The teacher teaches according what stated in the textbook. She should add some more teaching techniques, invent new test-taking techniques, and change her teaching style." Many researchers including Crandall (1979); Musumeci (1997); Anderson (1999); Nunan (1999); Richards \& Rodgers (2001); Burt, Peyton, \& Adams (2003); and Chalaysap (2011); among many others, all suggest that instructors should devise an appropriate way to suit their students' needs. According to these professionals, in addition to materials, teacher should reflect their personal practices as well. This can certainly be an interesting dimension of futuristic research.

\section{Conclusions}

The responses of the participants in the present study is prone to accord with Child's (1988), Mikulecky's (1990), Musumeci's (1997), and Sosothikul's (2007), to mention a few, concept that, even though approximately half Master's degree students in the course LC 4001: Reading Skills Development in English for Graduate Studies in this study were competent in English, some still required reading readiness prerequisites. Despite the fact that many students found the textbook appropriate, they proposed some suggestions about preconditions of grammar and vocabulary. As mentioned earlier, students at NIDA are admitted by different criteria, e.g. written examination only, written examination plus interview, interview only, and GPA. Students in English may need some more preparations for the LC 4001 course, such as essential grammar rules, word power, or even bilingual subtitles for some lessons. These findings are evidenced by the respondents' answers to the open-ended question. That is, whether the answer is 'appropriate,' 'too easy,' or 'too difficult;' almost all of the students seemed to have similar additional comments. In general, most of them mentioned the lack of some necessary basic lessons including grammatical elements and key concepts like noun clause, vocabulary expansion, and reading comprehension like main ideas. Many respondents called for an update of the textbook and a basic grammar course.

As found in Andersen's (1999) work, the findings in the current study divulged that many articles in LC 4001 textbook are old-fashioned, for instance, an article therein written in 1989. Time is also another factor ruining the learning attainment. The research showed that too many topics in the textbook made the instructors rush their teaching. This is another problem for weak students to catch up with. Even the students favoring the textbook saw the incompatibility between the length of the textbook (210 A4-pages) and the course period (45 hours). The course administrator/director or policy maker should take these constructive comments into their consideration when revising the course. For the matter of fact, these comments call for immediate revision of the textbook because it does not match learners' needs, interest, and abilities (Andersen, 1999). Nonetheless, the fact that the participants came from only two groups of LC 4001 students requires further research to be conducted with the entire group of approximately $300-400$ students. 
It is also interesting to know the students' personal perspectives about the course in which they enrolled. Truly, some comments may be hard for course administrators to work out because adherence to such comments may end up in using Thai only in the English instruction. This practice may further hamper their English learning. Without adequate and proper preparation of English acquisition and learning, it is quite hard for Thai students to master English and compete in AEC (Onwimon, 2013). However, these comments help the co-authors, educators, or even the course directors/administrators to turn around and learn the truth that the LC 4001 group of students is proved to be a mixed-ability class. There are still a large number of students whose English literacy is quite low and who need some prerequisite courses. Many students lack basic grammatical knowledge. They don't even know different types of clauses which are basic elements in a sentence. Hence, some courses to pave their strong foundation are apparently needed. Grouping students based on their school may be cost-effective, but impractical in the aspect of second language development.

The need for bilingual textbooks is apparently mentioned in all options. Providing a basic grammar course may be an interesting solution to weak students. They all full-time students; therefore, adding another prerequisite course may be not a burden for them. However, all new introduction of the course must be planned and performed with cautions because these new courses may impinge advancement of other content subjects. It is thus not a matter of foundation only, but time as well. To master a difficult language with numerous exceptions like English really take time. Students should be aware of this fact. To make their English learning meaningful, they should set up their learning goals first. For instance, they can look up to the TOEIC score of $600+$. They should set personal goals to be able to read and write well, especially in business communication. With such tangible goal, their English learning will become more significant (see Crandall, 1979; Child, 1988; Mikulecky, 1990; Musumeci, 1997; Nunan, 1999; Richards \& Rodgers, 2001; Burt, Peyton, \& Adams, 2003; and Chalaysap, 2011; for instance).

Teaching English to students is hard, teaching a mixed-ability class is even much more difficult. If the students are taught based on their real English proficiency, will there be any other problems arisen from such grouping methods? If students are grouped based on their school/field of study, then why is the textbook the same? Some contents may fit some groups of students and some fields of study. If students are grouped by their school, then why is there no textbook provided specifically for them? To be precise, some public administration students may ask why they have to read some complicated business articles full of numerical statistics. Nowadays, there are plenty of multicolored updated textbooks, for instance, Advanced Reading Power by Beatrice S. Mikulecky \& Linda Jeffries (2007), or Well Read: Skills and Strategies for Reading by Mindy Pasternak, Elisaveta Wrangell, Laurie Blass, Kate Dobiecka, and Karen Wiederholt (2008). For update and attraction, the course administrator may take these books into consideration.

Since LC 4001 course is the one for all students of all fields of study and all students will take the same test, it is hard for instructors to decide which topics they should emphasize or which ones they can skip. Theoretically, to be able to read well, students should read extensively. However, it is hard to make these students understand the real purpose of learning to read effectively. As an old saying read, "Practice makes perfect." Likewise, for reading: the more frequency, the higher fluency. With such high readability, students can read anything and understand it without any hardship. Most students simply take the English course because it is required. They do not learn the language because they see its importance to their life or at work. Their answers comparing the test and the textbook apparently reveal a traditional attitude towards English learning that students usually use the test as the benchmark of their study rather than their extra ability in English reading comprehension for global communication, brighter future, or even better-paid job at the end of their study. As a consequence, there should be both improvement in terms of the textbook update and the students' correct attitude toward English learning.

The pedagogical style of the non-native English instructors is also brought into play even though this study does not highlight their pedagogical approaches. A student clearly mentioned that she resented the teaching method. This is significant because it can be another research study focusing on the teaching method employed by an instructor.

With numerous challenges, non-native English-language instructors have to try harder and become more energetic to teach their students. It may be hard to find the best solutions, but we all teachers have to do something we can one by one to make that happen. It may be hard at the beginning, but when time passes, novel matters will become more and more familiar. Such familiarity makes things much easier than ever before. We, co-authors, are encouraging you all instructors to find the best way for our students to become fluent in English skills, not in reading only but in all skills. With such abilities, all our students will become confident in their communication for better understanding in the global village and that is not only their ultimate goals but ours.

\section{Acknowledgements}

The co-authors would like to express their deepest appreciation to all LC 4001 students who wholeheartedly participated in this research study for the betterment of the course in the future. They deeply 
appreciate the Graduate School of Language and Communication, the National institute of Development Administration (NIDA) for academic freedom which allows them to apply many educational approaches to make the class succeed in the objectives. Full responsibility for any remaining shortcomings is entirely theirs.

\section{References}

[1]. 2013 University Web Rankings. (2013). Universities in Thailand. Retrieved on February 2, 2013 from http://www.4icu.org/th/

[2]. Anderson, N. (1999). Exploring second language reading: issues and strategies. Canada: Heinle \& Heinle Publishing, Inc.

[3]. Burt, M., Peyton J. K., \& Adams, R. (2003). Reading and adult English language learners: a review of the research. USA: Center for Applied Linguistics.

[4]. Chalaysap, N. (2009). A comparative study between syntactic structure identification training and integrated reading strategy training in teaching English sentence reading. The Asian EFL Journal Cebu Conference Proceedings, August, pp. 43-56.

[5]. Chalaysap, N. (2011). Reading behavior of Master's degree students: A case study of the National Institute of Development Administration. NIDA Development Journal, 51(3), pp. 167-186.

[6]. Chalaysap, N., Swangboonsatic, C., Getkham, K., Suwanarak, K., Jaturongkachoke, K., Sena, K., Klamphonchira, N., Rojjanaprapayon, R., Saengboon, S., Gadananij, S., and Sagaravasi, V. (2010). ELT Innovation: Students' Participation in Generating Academic Reading Materials. Proceedings of the International Conference of Language and Communication (ICLC 2010), Bangkok, Thailand, pp. 184-194.

[7]. Chanseawrassamee, S. (2012). Teaching adult learners English through a variety of activities: Perception on games and rewards. USChina Foreign Language, 10(7, July), ISSN 1539-8080, pp. 1355-1374.

[8]. Child, J. (1988). IV Reading proficiency assessment: Section 1: Framework for discussion. In P. Lowe, Jr. and C. W. Stansfield (Eds.), Second language proficiency assessment: Current issues (pp. 125-135). New Jersey: Prentice Hall Regents.

[9]. Connolly, P. (2009). The challenges and prospects foreducational effectiveness research. Effective Education, 1(1, March), pp. 1-12.

[10]. Crandall, J. (1979). Language in education: theory \& practice (adult vocational ESL). US: Center for Applied Linguistics (CAL).

[11]. Eskey, D. E. (1986). Theoretical foundations. In F. Dubin, D. E. Eskey, and W. Grabe (eds.), Teaching second language reading for academic purposes. Reading, MA: Addision-Wesley Publishing Company, pp. 3-23.

[12]. Graduate School of Language and Communication. (2012). LC 4001: Reading skills development in English for graduate studies. Bangkok: NIDA Press.

[13]. Heller, M. (1997). Language choice and symbolic domination. In B. Davies \& D. Corson (Eds.), Encyclopedia of language and education, vol. 3: Oral discourse and education (pp. 87-94). Dordrecht, Netherlands: Kluwer.

[14]. Izzo, S. (1981). Second language learning: A review of related studies. Virginia: National Clearinghouse for Bilingual Education.

[15]. Jaturongkachoke, K. \& Chanseawrassamee, S. (2012). Powerful impact of YouTube upon presentation skill development of MBA students. Proceedings of the Fourth Asian Conference on Education (ACE 2012). Osaka, Japan, October 24-28, pp. 905-926.

[16]. Mikulecky, B. S. \& Jeffries, L. (2007). Advanced reading power. New York: Pearson Longman.

[17]. Mikulecky, B. S. (1990). A short course in teaching reading skills. USA: Addison-Wesley Publishing Company.

[18]. Ministry of Education. (2007). Ministry of Education informs the information about the Reading Festival at the Ministry of Education. Retrieved on February 2, 2013 from http://www.moe.go.th/English/News/eng05062550_1.htm

[19]. Musumeci, D. (1997). Breaking tradition: An exploration of the historical relationship between theory and practice in second language teaching. USA: McGraw-Hill.

[20]. National Institute of Development Administration. (2008). Annual Report 2008. Bangkok: NIDA Press.

[21]. National Institute of Development Administration. (2013). Commencement Brochure: Message from the President. Bangkok: NIDA Press.

[22]. Nunan, D. (1999). Second language teaching \& learning. Boston: Heinle \& Heinle Publishers.

[23]. Office of the Education Council, Ministry of Education, Kingdom of Thailand. (2007). Education in Thailand 2007. Bangkok: Amarin Printing and Publishing.

[24]. Office of the Educational Council, Ministry of Education, Kingdom of Thailand. (2011). Strategy in production and developing workforce of the nation in the second decade of education reform B.E. 2009-2018. Bangkok: Office of the Educational Council.

[25]. Onwimon, S. (February 8, 2013). Thai Children Don't Enter into and Ready Themselves for the Challenges of AEC. Koosangkoosom, 783, pp. 46-47.

[26]. Pasternak, M., Wrangell, E., Blass, L., Dobiecka, K., \& Wiederholt, K. (2008). Well Read: Skills and strategies for reading. Now York: Oxford University Press.

[27]. Peregoy S. F. \& Boyle, O F. (2001). Reading, writing, \& learning in ESL: A resource book for K-12 teachers (3rd ed.). USA: Addison Wesley Longman, Inc.

[28]. Pison, A. (May 16, 2011). Reading enables us to know each other. Eduzone New Networks. Retrieved on November 8, 2012 from http://www.enn.co.th/136

[29]. Richards, J. C., \& Rodgers, T. S. (2001). Approaches and methods in language teaching (2nd ed.). Cambridge: Cambridge University Press.

[30]. Rigg P. \& Kazemak, F. E. (1993). Whole language in adult literacy education. In J. Crandall \& J. K. Peyton (Eds.), Approaches to adult ESL literacy instruction (pp. 35-46). USA: Center for Applied Linguistics and Delta Systems Co., Inc.

[31]. Savage, K. L. (1993). Literacy through competency-based educational approach. In J. Crandall \& J. K. Peyton (Eds.), Approaches to adult ESL literacy instruction (pp. 14-33). USA: Center for Applied Linguistics and Delta Systems Co., Inc.

[32]. Silberstein, S. (1993). Techniques and resources in teaching reading. New York: Oxford University Press.

[33]. Sosothikul, R. (2007). How to improve your reading. Bangkok: Chulalongkorn University Press.

[34]. Thai Government. (1999). National Education Act B.E. 2542 (1999). Bangkok.

[35]. Triamudomsuksanomklao School, Bangkok. (2012). Educational curriculum of world-class standard school. Bangkok: Triamudomsuksanomklao School.

[36]. Vathakanon, S. (2005). How to read and (not) understand English (2nd ed.). Bangkok: Thammasat University Press. 